American J. of Engineering and Applied Sciences 3 (2): 286-292, 2010

ISSN 1941-7020

(C) 2010 Science Publications

\title{
Numerical Modeling of Flow in a Horizontal Sand Filter
}

\author{
${ }^{1}$ Ruth Mossad and ${ }^{2} \mathrm{Hal}$ Aral \\ ${ }^{1}$ Faculty of Engineering and Surveying, \\ University of Southern Queensland, Australia \\ ${ }^{2}$ CSIRO Process Science and Engineering Division, \\ Bay View Ave Clayton 3169, Victoria, Australia
}

\begin{abstract}
Problem statement: Horizontal sand filters may offer some advantage over vertical sand filters as they could be used for in-line treatment of wastewaters. Horizontal pipelines of tens and if not hundreds of meters length, filled with ordinary sand or permeable reactive media such as activated carbon or natural zeolite or iron filings, may be used to remove impurities from mine drainage waters, sewer and storm waters. Approach: However, in reality, in industrial-scale applications, the sand filled horizontal structures are almost always avoided due to the fact that water seeks out the path of least resistance. Once such a path is created, the vast majority of the water channels towards the least resistance zone and very small percentage of the water will go through the sand. Results: This study, applying numerical modeling using FLUENT software, which is based on the integral control volume approach, explores a number of geometries to identify a design that helps the inlet water to sweep the entire sand with the least channeling. The Navier Stokes equations for laminar and incompressible flow through porous media (i.e., the sand) including the viscous resistance were solved. Retention time of a fluid with properties similar to water, called tracer, were also estimated using Eulerian unsteady two phase flow analysis. Conclusion: The results of the models showed that the geometries involving a pipe with spiral protrusions or plate (baffles) inside, would be partially successful in drawing the water away from the channeling zone and moving it through the sand, however the geometry with the spiral protrusions uses much less power than the one with the baffles.
\end{abstract}

Key words: Horizontal flow, laminar flow, numerical modeling, porous media, wastewater

\section{INTRODUCTION}

Although the flow of water through vertically standing sand filters has been studied in detail and applied commercially to remove particulate matter from wastewaters, little is known about the movement of water through sand in horizontal pipes. Flow in porous media such as sand filters plays an important role in many science and engineering fields; for example: In reservoir engineering, waste water treatment in environmental sciences, hydrology, biomechanics, geophysics, hydraulics, soil mechanics and in chemical, aeronautical and petroleum engineering. Various aspects of the flow through porous media and the relationship between flow and pore structure have been reviewed by many authors including Bear (1972); Slattery (1972); Scheidegger (1960); Collins (1961); Happel and Brenner (1965); Dullien (1975); Shijie et al. (1994) and As et al. (1998). The specific resistance of a porous medium to the passage of single-phase fluids under the influence of a pressure gradient is the property that has received the greatest attention (Dullien, 1975).

Sand filters are commonly used in industrial wastewater and urban water treatment. According to Wegelin (1983) and Barrett and Borroum (2001) sand filters can be classified based on the size of the sand. They can be slow sand filters (diameter $=0.15-0.35 \mathrm{~mm}$ ), rapid sand filters (diameter $0.5-2 \mathrm{~mm}$ ) and roughing sand filters (diameter $>2 \mathrm{~mm}$ ). The performance, running cost and maintenance requirements of vertical filters have been investigated by various authors. Barrett and Borroum (2001) and Pratap et al. (2005) looked at improving the performance of sand filters and enhancing the quality of water by using up flow, instead of down flow, Rooklidge (2003) and Wegelin (1983) using roughing filters.

Horizontal sand filters may offer a better way of treatment of wastewater such as those drained from mine tailings since they can be used in-line and have no

Corresponding Author: Ruth Mossad, Faculty of Engineering and Surveying, University of Southern Queensland, Australia Tel: +61 746312615 Fax: +61 746312526 
limit on their length such as the case with vertical filters. Horizontal pipelines of tens and if not hundreds of meters length, filled with ordinary sand or other media such as activated carbon or natural zeolite or iron filings, may be used to remove impurities from mine drainage water, sewer and storm water.

In sand filled horizontal structures a least resistance path is created mainly due to the settlement (compaction) of the sand bed upon getting wet (a gap is created on top of the sand). The lab-scale experiments show that a small air gap almost always remains even though the pipe is filled with wet sand and compacted by vibration or other means. This least resistance path is preferred by the flowing water, which greatly reduces the effectiveness of horizontal sand filters.

Prediction of water flow and solute transport in heterogeneous media is further complicated by the presence of micro-and macro-pores (Mallants et al., 1996). Many contaminants move through the media in particulate or colloidal form, either because they are inherently fine particulate or precipitate due to their low solubility or because they are adsorbed onto other mobile particles which are present in the soil (McGechan and Lewis, 2002). Particulate and contaminant movement through micro-and macro-pores leads to straining or filtration of particulate (colloidsorbed) contaminants. The precipitation of fine particulate between the macro-pores eventually fills the inter-aggregate pore spaces and hinders the movement of the water freely. This could especially be the case if the permeable media reacts with the water as in the case of some acid mine drainage waters.

In this study various geometries were modeled to understand the movement of water in a horizontal sand filter. The objectives of this study are to identify the geometry that minimizes channeling and enhances the performance of the filter. The modeling was done using FLUENT software. In this model, water is assumed to move around the grains without any hindrance imposed by compositional changes and presence of air bubbles was not considered.

\section{MATERIALS AND METHODS}

Mathematical model: The water flow is governed by the conservation laws such as continuity equation and momentum equations in three dimensions $\mathrm{x}, \mathrm{y}$ and $\mathrm{z}$. These equations under the assumptions of steady, incompressible, laminar and Newtonian flow, including the effect of gravity, are expressed in Eq. 1-4, as follows:

$$
\frac{\partial u}{\partial x}+\frac{\partial v}{\partial y}=0
$$

$$
\begin{aligned}
& u \frac{\partial u}{\partial x}+v \frac{\partial u}{\partial y}+w \frac{\partial u}{\partial z}=-\frac{1}{\rho} \frac{\partial p}{\partial x}+v\left(\frac{\partial^{2} u}{\partial x^{2}}+\frac{\partial^{2} u}{\partial y^{2}}+\frac{\partial^{2} u}{\partial z^{2}}\right)+S_{x} \\
& u \frac{\partial v}{\partial x}+v \frac{\partial v}{\partial y}+w \frac{\partial v}{\partial z}=-\frac{1}{\rho} \frac{\partial p}{\partial y}+v\left(\frac{\partial^{2} v}{\partial x^{2}}+\frac{\partial^{2} v}{\partial y^{2}}+\frac{\partial^{2} v}{\partial z^{2}}\right)+S_{y} \\
& u \frac{\partial w}{\partial x}+v \frac{\partial w}{\partial y}+w \frac{\partial w}{\partial z}=g+-\frac{1}{\rho} \frac{\partial p}{\partial z} \\
& +v\left(\frac{\partial^{2} w}{\partial x^{2}}+\frac{\partial^{2} w}{\partial y^{2}}+\frac{\partial^{2} w}{\partial z^{2}}\right)+S_{z}
\end{aligned}
$$

In these equations:

$\mathrm{u}, \mathrm{v}$ and $\mathrm{w}=$ The velocities in the $\mathrm{x}, \underset{-1}{\mathrm{y}}$ and $\mathrm{z}$ directions respectively, $\mathrm{m} \mathrm{sec}^{-1}$

$\mathrm{p} \quad=$ The pressure, $\mathrm{Pa}$

$\rho \quad=$ The fluid's density, $\mathrm{kg} \mathrm{m}^{-3}$

$\mathrm{g} \quad=$ The gravitational acceleration, $\mathrm{m} \mathrm{sec}^{-2}$

$v \quad=$ The kinematic viscosity of the fluid, $\mathrm{m}^{2} \sec ^{-1}$

$S_{\mathrm{x}}, \mathrm{S}_{\mathrm{v}}$ and $\mathrm{S}_{\mathrm{w}}=$ Source terms that represent the effect of the porous media on the pressure drop

$\mathrm{x}$-axis $=$ Aligned with the horizontal direction i.e., along the main axis of the filter

$\mathrm{y}$-axis $\quad=$ Perpendicular to the paper

z-axis $\quad=$ Aligned with the vertical direction

The source terms are composed of two parts: A viscous loss term (Darcy, the first term on the righthand side of Eq. 5) and an inertial loss term (the second term on the right-hand side of Eq. 5) where $S_{i}$ is the source term for the $\mathrm{i}^{\text {th }}$ momentum equation (i.e., $\mathrm{x}, \mathrm{y}$ or $\mathrm{z}$ ) and $\mathrm{D}$ and $\mathrm{C}$ are viscous resistance and inertial resistance coefficients, respectively and $\mu$ is the dynamic viscosity. This momentum sink contributes to the pressure gradient in the porous cell, creating a pressure drop that is proportional to the fluid velocity (or velocity squared) in the cell:

$S_{i}=-\left(\sum_{j=1}^{3} D_{i j} \mu v_{j}+\sum_{j=1}^{3} C_{i j} \frac{1}{2} \rho v_{m a g} v_{j}\right)$

The viscous resistance $\mathrm{D}$ was estimated from the permeability of the sand $\mathrm{K}$ as $1 /$ permeability. Since laminar flow was assumed within the porous media, the inertial resistance $\mathrm{C}$ was ignored, as recommended by the FLUENT 4.4 User's Guide (1997) and $\mu$ is the dynamic viscosity of the fluid, N.s $\mathrm{m}^{-2}$.

To predict the flow through the filter these equations need to be solved simultaneously. The above governing equations are non-linear, partial differential equations for which a closed form solution is not 
possible so a numerical solution was used in this study. The computational fluid dynamics software FLUENT was used to solve these equations. FLUENT uses a control volume based finite difference method. The governing equations are discretised on a curvilinear grid to enable computations in a complex domain. Interpolation of convection fluxes is accomplished via a first-order Power-Law scheme or optionally via a higher order upwind scheme. In this work, the first order upwind scheme was used for the momentum equation. The equations are solved using a SemiImplicit algorithm (SIMPLE) with an iterative line-byline matrix solver. The details can be found in FLUENT 4.4 User's Guide (1997). Number of cells used varied with the geometry and they ranged from 1.8-3.75 million cells.

Sand was assumed to have porosity, $\varepsilon$, of $20 \%$, which is used to calculate the permeability $\mathrm{K}$ according to the equation given by Vafai (1994) for spherical particles with diameter $\mathrm{d}$ as:

$$
\mathrm{K}=\varepsilon^{3} \mathrm{~d}^{2} /\left(147 \times(1-\varepsilon)^{2}\right)
$$

The differential equations representing the flow were solved numerically using the following boundary conditions: (a) at the walls of the filter, a non-slip condition was enforced (b) at inlet a uniform velocity was chosen to give the same flow rate in each case modeled and (c) at the exit a constant atmospheric pressure was applied.

In order to judge the effectiveness of each design, the retention time of a tracer flowing in each case was estimated using the following approach. After a steady state solution for the water flow through the porous media (sand) was obtained in each design, a non steady solution was started. A tracer with water properties was injected at the inlet with $10 \%$ volume fraction and it was monitored as time progressed. The time at which $10 \%$ of the tracer has reached the outlet of each design was recorded. The Eulerian multiphase model was used for modeling the two phase flow of water and tracer. The FLUENT solution is based on a single pressure shared by both phases (water and tracer) and the momentum and continuity equations are solved for each phase including the interaction between the two phases, such as drag forces. Details can be found in FLUENT 4.4 User's Guide (1997).

\section{RESULTS}

Sand filter designs and results: The numerical solution predicts velocities in the $\mathrm{x}, \mathrm{y}$ and $\mathrm{z}$ directions (i.e., $\mathrm{u}, \mathrm{v}$ and $\mathrm{w}$ velocity components) and pressures, $\mathrm{p}$, at predetermined nodes in the domain. These allow an estimate of the amount of flow that has channeled in each case and the pressure difference across the filter and the corresponding power needed to run the flow in each geometry.

Different geometries were examined (Fig. 1) and modeled to find out an effective way to enhance the performance of horizontal sand filters that minimizes the channeling. The basic geometry is a $10 \mathrm{~m}$ long pipe with $0.2 \mathrm{~m}$ diameter. Four different geometries were considered and in all cases the sand was assumed to be originally wet and filled only $95 \%$ of the pipe compactly. The sand assumed to have a porosity of $20 \%$, particle size of $\mathrm{d}_{50} 300 \mu \mathrm{m}$ and viscous resistance coefficient of $1.3 \times 10^{11}$. The $5 \%$ at the top of the pipe was modeled as if it were filled with sand with much lower viscous resistance to the flow; namely, around 2 orders of magnitude $\left(1.0 \times 10^{9}\right)$ less than the underlying compact sand. The reason for this is to be able to consider the flow in the whole pipe as flow through a porous media but with varying resistance, instead of flow partially through porous media and partially through an open pipe to avoid any instability of the numerical model. A flow rate of $0.31 \mathrm{~kg} \mathrm{sec}^{-1}$ $\left(\sim 26.8 \mathrm{~kL} \mathrm{day}^{-1}\right)$ was assumed in all designs giving an average velocity inside the main pipe of $0.01 \mathrm{~m} \mathrm{sec}^{-1}$.

Geometry 1a-base scenario a: In this base case scenario, the main pipe is $10 \mathrm{~m}$ long and $0.2 \mathrm{~m}$ diameter and assumed to have one meter long inlet and one meter long outlet with $0.04 \mathrm{~m}$ diameter placed at the opposite ends. The inlet pipe was positioned at the bottom right hand side of the pipe and the outlet at the top left end of the pipe as shown in Geometry 1a in Fig. 1.

The results show that the flow has channeled to the top where the high porous zone is (top 5\% of the main pipe). The flow has high velocities at the top and very low velocities within the compact sand.

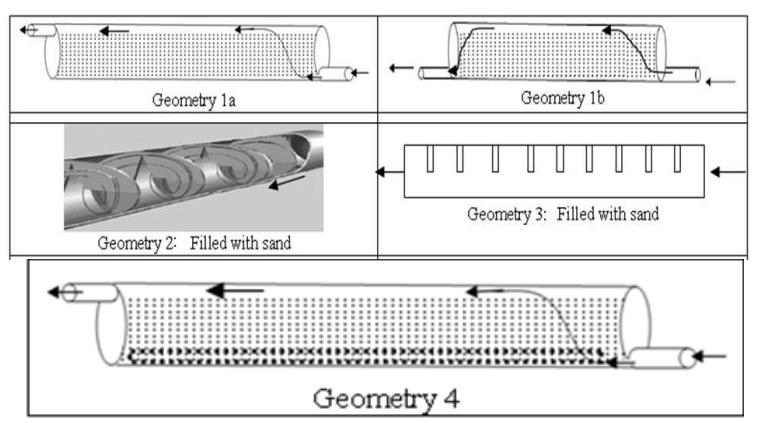

Fig. 1: Various geometries investigated by FLUENT modeling 


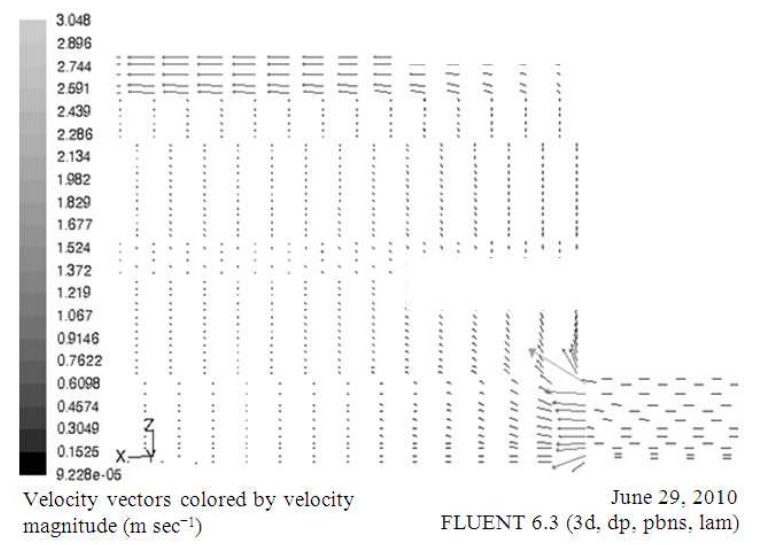

(a)

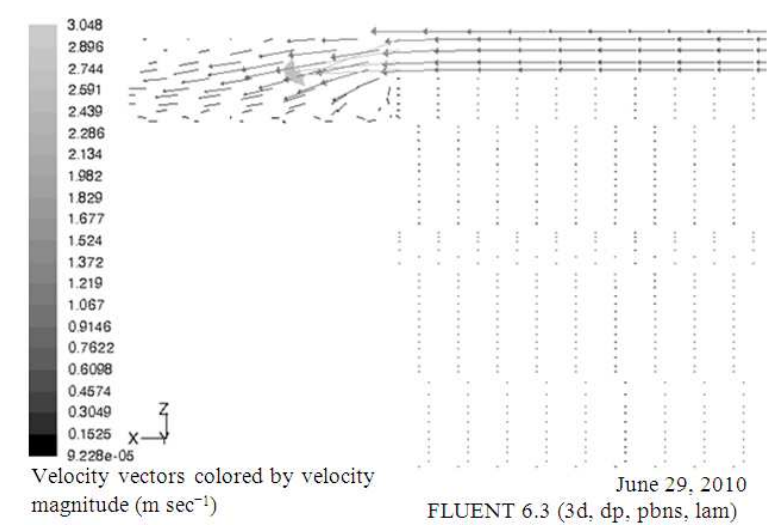

(b)

Fig. 2: Velocity vectors in the mid-plane at inlet (a) and at outlet; (b) of Geometry 1a

Figure 2a shows the velocity vectors at the inlet zone of this filter and how quickly the flow directs itself towards the low resistance zone of the pipe. Figure $2 b$ shows the details of the velocity vectors at the outlet zone of this filter, where the flow accelerates to get out of the exit since the exit pipe did not have any porous media resisting the motion of the flow.

Geometry 1b-base scenario b: In this base case scenario, the main pipe ( $10 \mathrm{~m}$ length, $0.2 \mathrm{~m}$ diameter), similar to the Geometry 1a, is assumed to have a one meter long inlet and one meter long outlet with $0.04 \mathrm{~m}$ diameter placed at the opposite ends. The only difference is that the inlet and the outlet pipes were both positioned at the bottom as shown in Geometry $1 \mathrm{~b}$ in Fig. 1.

The results show that the flow has channeled to the top, where the high porous zone is (top $5 \%$ of the main pipe) as shown from the velocity vectors at the inlet zone of this filter and how quickly the flow directs itself towards the low resistance zone of the pipe (Fig. 3a).

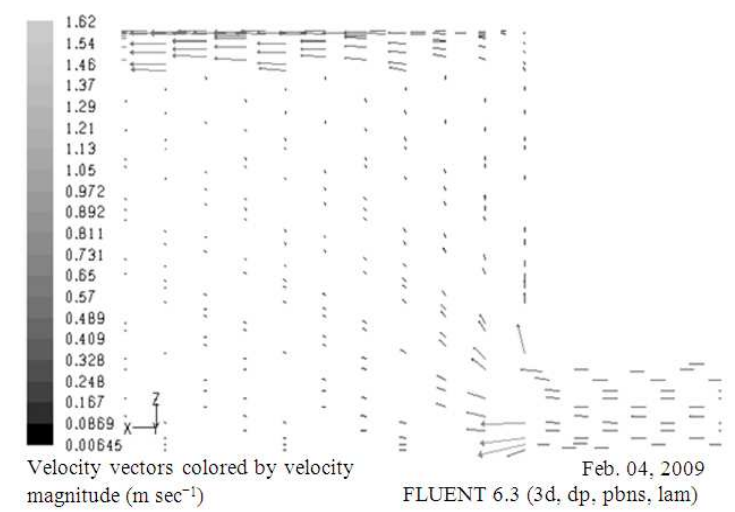

(a)

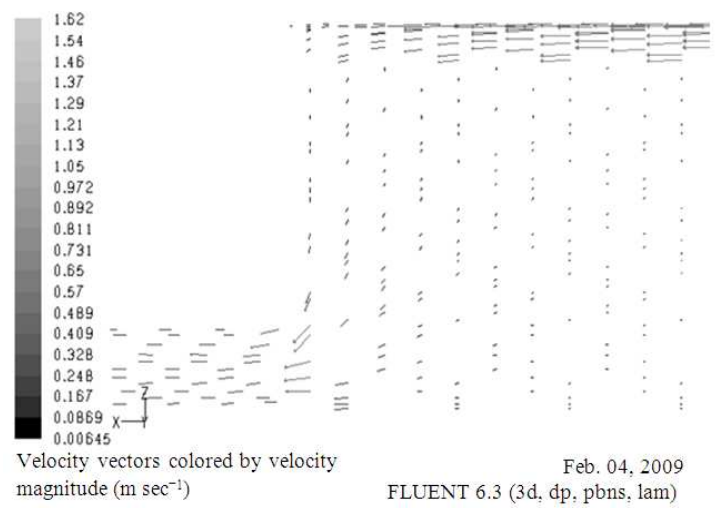

(b)

Fig. 3: Velocity vectors in the mid-plane at inlet (a) and at outlet; (b) of Geometry 1b

Figure $3 b$ shows the details of the velocity vectors at the outlet zone of this filter, where the flow accelerates to get out of the exit since the small exit pipe does not have any porous media resisting the motion of the flow. It is to be noticed that the maximum velocity of the water here is lower than that in Geometry $1 \mathrm{a}$.

The scenarios $1 \mathrm{a}$ and $1 \mathrm{~b}$ show that alternative designs should be considered to ensure the inlet water uniformly sweeps the entire body of the sand at the given flow rate of $0.31 \mathrm{~kg} \mathrm{sec}^{-1}$. The other geometries modeled are discussed below.

Geometry 2-spiral baffle: In this case, one spiral protrusion with a depth of $0.02 \mathrm{~m}$ and a pitch of $1 / 360 \mathrm{~m}$ was added inside the main pipe (Fig. 1). The spiral was to re-direct the water moving to the least resistance zone to sink towards the bottom of the pipe.

The velocity vectors in a vertical mid plane of this design (Fig. 4) again showed flow channeling to the top where the porous media has low resistance, but with some interrupted zones, which seems to be around the spiral blade. It seems that the flow was forced to sink locally in the vicinity of the blade but moved up again to the low resistance zone. 
Am. J. Engg. \& Applied Sci., 3 (2): 286-292, 2010

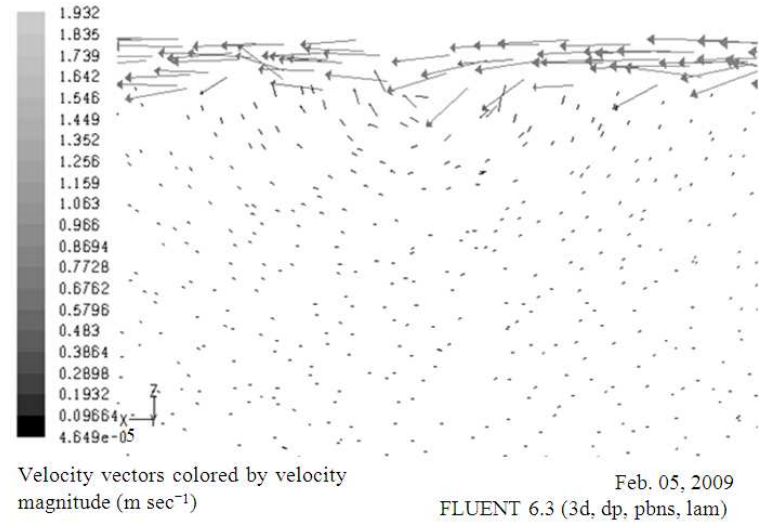

Fig. 4: Details of velocity vectors around the spiral of Geometry 2

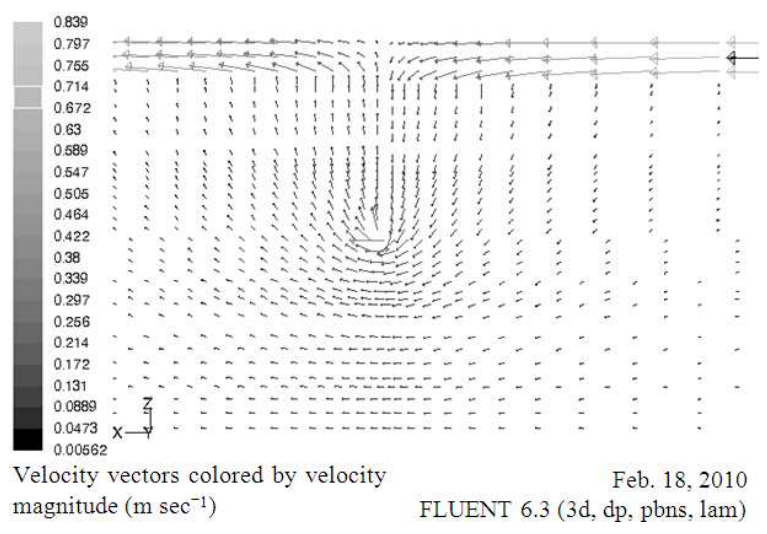

Fig. 5: Details of velocity vectors around the baffle of Geometry 3

Geometry 3-plate baffles: A set of baffles in the shape of half circles were added to the top part of the pipe at 1 $\mathrm{m}$ intervals (Fig. 1). These baffles managed to force the water to go down through the sand but only locally, where the velocity of the water was increased around the baffle but in between each baffle the water moved again up to the lowest resistance zone (Fig. 5).

Geometry 4-coarse sand bottom: Geometry 4 is the basic geometry (namely Geometry 1a) which is $10 \mathrm{~m}$ long pipe with $0.2 \mathrm{~m}$ diameter, without the inlet and the outlet pipes. At the bottom of the pipe a coarse material was placed with porosity close to $45 \%$ to create another low viscous resistance zone five times the viscous resistance assumed for the gap on top of the bed. The purpose of this second low resistance zone was to force the water (at least partially) to go down through the sand instead of channeling to the top.
Table 1: Retention time of the tracer in the different geometries

\begin{tabular}{lc}
\hline Geometry & Retention time (sec) \\
\hline Basic Geometry 1a & 40 \\
Basic Geometry 1b & 51 \\
Spiral Geometry 2 & 3900 \\
Baffle Geometry 3 & 1200 \\
Geometry 4 & 316 \\
\hline
\end{tabular}

Again the flow did channel and this time at both places where the low resistance existed, i.e., at the top and at the bottom of the pipe. The velocities at the top were the largest and at the bottom they were medium and they were the smallest at the middle where the highest resistance existed.

Retention time: The above geometries were investigated using a tracer to estimate the retention time of the tracer inside these designs. A tracer with properties of water was inserted at the inlet with $10 \%$ volume fraction and modeled using the Eulerian approach as mentioned before and was monitored using unsteady analysis. The time at which $10 \%$ of the tracer has reached the outlet was recorded. These results are given in Table 1.

Comparing the retention time obtained for the geometries studied, Table 1, show that Geometry 2 has the highest retention time, which means that it will outperform the other geometries in filtering the water since it had more time inside the filter.

Flow in the middle vertical plane: The effectiveness of the different geometries was also assessed based on the velocities in the middle vertical plane. The velocity, $\mathrm{u}$, within the sand in the horizontal direction, $\mathrm{x}$, shows how much of the water is flowing straight through the sand while the velocity, $w$, in the vertical direction $z$, shows how the flow is sweeping the body of the sand at that location. A line perpendicular to the flow direction, in the middle of the $10 \mathrm{~m}$ main pipe was chosen for this comparison. Figure 6 and 7 show a comparison of these velocities in the different geometries proposed. These investigations showed that there was very little movement of the water through the sand in both directions (i.e., small $\mathrm{u}$ and $\mathrm{w}$ velocities). However, Geometry 2, the geometry with the spiral, has higher u-velocities within the compacted sand than the other geometries. In the vertical direction it also has much higher w velocities. Note that the high velocity zone for Geometry 4 is within the lower part of the filter which has a medium with higher porosity.

Pressure and power requirements: For all geometries investigated the average velocity in a vertical plane in the middle of the pipe was estimated and compared to judge the effectiveness of the proposed geometry, namely reducing the amount of water channeling. Another parameter of interest has been estimated is the power needed to pump the water through these different geometries. 
Am. J. Engg. \& Applied Sci., 3 (2): 286-292, 2010

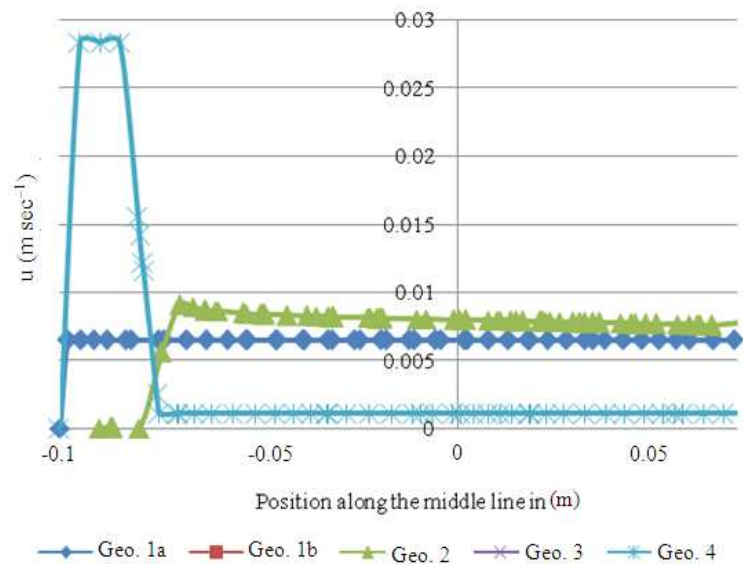

Fig. 6: Comparison of the $u$ velocity along a line perpendicular to the flow direction, in the middle of the main pipe

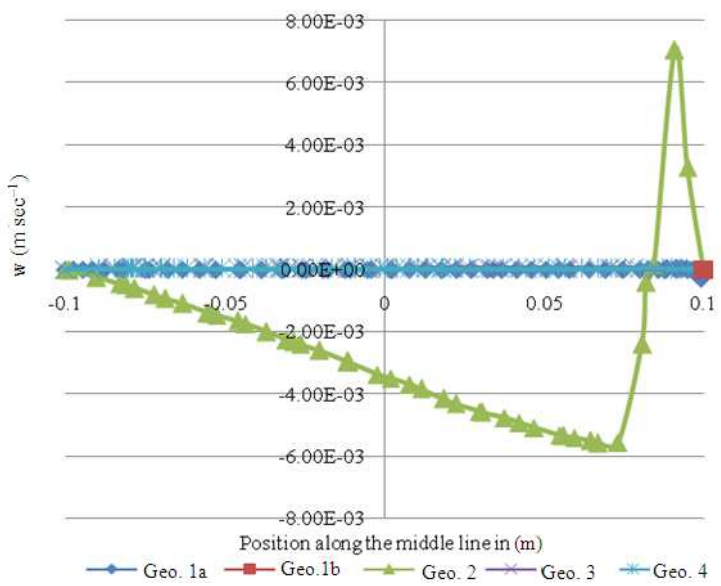

Fig. 7: Comparison of the $w$ velocity along a line perpendicular to the flow direction, in the middle of the main pipe

In Geometry $1 \mathrm{a}$ and $1 \mathrm{~b}$, the flow channeled to the top in the first $0.5 \mathrm{~m}$. The average velocity of the flow in the gap at the top was high $\left(\approx 0.8 \mathrm{~m} \mathrm{sec}^{-1}\right)$. This estimation is based on the velocity distribution at a vertical line in the middle of the pipe. On the other hand, the average velocity of the flow within the main body of the sand was significantly low $\left(\approx 0.006 \mathrm{~m} \mathrm{sec}^{-1}\right)$, indicating that about $85 \%$ water was channeling to the top. At the end of the pipe in Geometry 1a the water existed at ease while it took about another 0.5 a meter to come down to the exit in Geometry 1b. However, this needed more pressure to push the water through the lower exit in Geometry $1 \mathrm{~b}$ than the top exit, in Geometry 1a and hence more power was required as can be seen in Table 2 .
Table 2: Pressure difference and power needed for each geometry

\begin{tabular}{|c|c|c|c|}
\hline Geometry & Mode & $\begin{array}{l}\text { Pressure difference } \\
\Delta \mathrm{p}(\mathrm{Pa})\end{array}$ & $\begin{array}{l}\text { Power } \\
\mathrm{P}=\Delta \mathrm{p}^{*} \mathrm{Q} \text { (watts) }\end{array}$ \\
\hline $1 \mathrm{a}$ & Only sand & 796,049 & 0247 \\
\hline $1 \mathrm{~b}$ & Only sand & $1,591,021$ & 0494 \\
\hline 2 & Spiral & $3,476,829$ & 1080 \\
\hline 3 & Baffle & $5,905,838$ & 1834 \\
\hline 4 & $\begin{array}{l}\text { Coarse sand } \\
\text { at bottom layer }\end{array}$ & 1,509503 & 0470 \\
\hline
\end{tabular}

For Geometry 2 and 3 the water was still channeling to the top where the lower resistance is, however the water was forced to go through the sand at a deeper level around the spiral and the baffles. For the spiral geometry, Geometry 2, around $40 \%$ of the water was channeled in the $5 \%$ top part of the pipe while in the baffle geometry, geometry $3,60 \%$ of the water channeled. It should be noted that Geometry 3 costs the most to run and Geometry 2 comes second in terms of power requirements as can be seen from Table 2 .

Geometry 4 shows the presence of more porous media at the bottom has diverted some of the water to be channeled at the bottom at an average speed of $0.028 \mathrm{~m} \mathrm{sec}^{-1}$ as well as the top at an average speed of $0.13 \mathrm{~m} \mathrm{sec}^{-1}$.

\section{DISCUSSION}

All proposed deigns have shown that water did channel to the least resistance zone. However, some designs were better than others, showing a less proportion of the water being channeled. Geometry 2 (spiral) has shown the least channeling, Geometry 3 (baffles) comes second on the expense of higher power usage in comparison to the other geometries.

Comparing the horizontal and vertical velocities, $u$ and $\mathrm{v}$, along a vertical line in the middle one can find that Geometry 2 shows promising results of being able to draw the water downward and through the sand to a limited extent, therefore enhancing the performance of the horizontal sand filters. Geometry 3 did not show high velocities at the chosen vertical line, the reason may be due to this line being exactly in the middle between two baffles where the effect of the baffles on the flow has diminished. Velocities at other positions in this particular design need to be investigated further. In spiral and baffle geometries, the sweep of the water through the sand may further be improved by closely spacing the protrusions, however this improvement would be at the expense of higher power needed to achieve the same flow rate.

Retention time study also proved that geometry 2 has the highest retention time which is again promising of better performance. 
Am. J. Engg. \& Applied Sci., 3 (2): 286-292, 2010

\section{CONCLUSION}

This study showed that Geometry 2, a pipe with spiral protrusions inside was partially successful in drawing the water downward and moving it through the sand reducing the percentage of the channeled water. The preliminary investigations suggest further studies are needed in terms of optimization of the choice of the spiral, its pitch and depth for Geometry 2. Furthermore, the optimized design geometries identified by the current modeling need to be experimentally verified and their ability to perform as a horizontal porous media filter should be demonstrated.

\section{ACKNOWLEDGEMENT}

The researchers would like to thank CSIRO MDU National Flagship Program (Project number R00585014-002) for their financial support. The authors would also sincerely thank Dr Peter Witt and Dr Graham Sparrow of CSIRO Minerals for their invaluable suggestions and editing.

\section{REFERENCES}

As, H.V., W. Palstra, U. Tallarek and D. van Dusschoten, 1998. Flow and transport studies in (non) consolidated porous (bio) systems consisting of solid or porous beads by PFG NMR. Magnet. Reson. Imag., 16: 569-573. DOI: 10.1016/S0730725X(98)00052-6

Bear, J., 1972. Dynamics of fluids in porous media. Fundamentals of transport phenomena in porous media. Elsevier, New York, ISBN: 0444998977, pp: 392.

Barrett, M.E. and J.S. Borroum, 2001. A preliminary assessment of the cost. Proceeding of the Maintenance Requirements and Performance of Sand Filters Resources Congress, May 20-24, Orlando, FL., pp. 1-24, DOI: 10.1061/40569(2001)196

Collins, R.E., 1961. Flow of fluids through porous materials. Reinhold, New York, ISBN: 0878140727, pp: 270.

Dullien, F.A.L., 1975. Single phase flow through porous media and pore structure. Chem. Eng. J., 10: 1-34. DOI: 10.1016/0300-9467(75)88013-0

FLUENT 4.4 User's Guide, 1997. ANSYS FLUENT Flow Modeling Software. Vol. 1-4, 2nd Edn., Fluent Incorporated. http://www.fluent.com/software/fluent/
Happel, J. and H. Brenner, 1965. Low Reynolds Number Hydrodynamics with Special Applications to Particulate Media. Prentice-Hall, USA., pp: 566.

Mallants, D., D. Jacques, M. Vanclooster, J. Diels and J. Feyen, 1996. A stochastic approach to simulate water flow in a macroporous soil. Geoderma, 70: 299-324. DOI: 10.1016/0016-7061(95)00084-4

McGechan, M.B. and D.R. Lewis, 2002. Transport of particulate and colloid-sorbed contaminants through soil. Part 1: General principles. Biosyst. Eng., 83: 255-273. DOI: 10.1006/bioe.2002.0125

Pratap, M., U. Khambhammettu, S.E. Clark and R. Pitt, 2005. Stormwater treatment using up-flow filters. Proceedings of World Water and Environmental Resources Congress, May 2005, ASCE Research Laboratory, Anchorage, Alaska, pp: 1-1. DOI: 10.1061/40792(173)227

Rooklidge, S., 2003. Passive slow sand filter amendments for clay removal and corrosion control. Proceedings of World Water and Environmental Resources Congress, June 23-26, ASCE Research Laboratory, Pennsylvania, pp: 1-1. DOI: 10.1061/40685 (2003)160

Scheidegger, A.E., 1960. The Physics of Flow through Porous Media. 3rd Edn., University of Toronto Press, Toronto, ISBN: 0802018491, pp: 353.

Slattery, J.C., 1972. Momentum, Energy and Mass Transfer in Continua. McGraw-Hill, New York, ISBN: 0882756109.

Shijie, L., A. Artin and M. Jacob, 1994. Steady incompressible laminar flow in porous media. Chem. Eng. Sci., 49: 3565-3586. DOI: 10.1016/0009-2509(94)00168-5

Vafai, K., 1994. Handbook of Porous Media. , 2nd Edn., Marcel Dekker Inc., Basel, New York, ISBN: 0-8247-8886-9, pp: 893.

Wegelin, M., 1983. Roughing filters as pre-treatment for slow sand filtration. Water Supply, 1: 67-75. 